\title{
Supporting Information: Electrocatalytic Hydrodechlorination of 2,4,5-Trichlorobiphenyl on a Palladium-Modified Nickel \\ Foam Cathode
}

BO YANG, GANG YU, AND JUN HUANG

Department of Environmental Science and Engineering, POPs Research Centre, Tsinghua University, Beijing 100084, China

Journal name: Environmental Science \& Technology

The Prepared Date: August 5, 2007

Five pages including the cover sheet, one table, and three figures 


\section{TABLE S1. ECH of 1 mM 2-PCB Using Various Surfactants}

\section{Concentration, $\mathrm{M} \quad$ 2-PCB conversion, $\%^{a} \quad$ Biphenyl yield, $\%$}

\begin{tabular}{|c|c|c|c|}
\hline CTAB & 0.1 & 73.6 & 66.1 \\
\hline Brij 30 & 0.1 & 77.8 & 69.4 \\
\hline SDS & 0.5 & 82.3 & 79.1 \\
\hline HPCD & 0.05 & 68.1 & 64.8 \\
\hline \multicolumn{4}{|c|}{$\begin{array}{l}{ }^{a} \text { ECH performed on the } \mathrm{Pd} / \mathrm{Ni} \text { foam cathode in } 30 \mathrm{~mL} \text { methanol/ } \mathrm{H}_{2} \mathrm{O}(50 \mathrm{vol} \%) \text { solution } \\
\text { containing } 0.1 \mathrm{M} \mathrm{NaAc}, 0.1 \mathrm{M} \mathrm{HAc} \text {, and surfactant at } 30^{\circ} \mathrm{C} \text { by constant current } 15 \mathrm{~mA} \text { with flow } \\
\text { rate of } 50 \mathrm{~mL} / \mathrm{min} \text { after } 20 \text { min electrolysis cut. }\end{array}$} \\
\hline
\end{tabular}



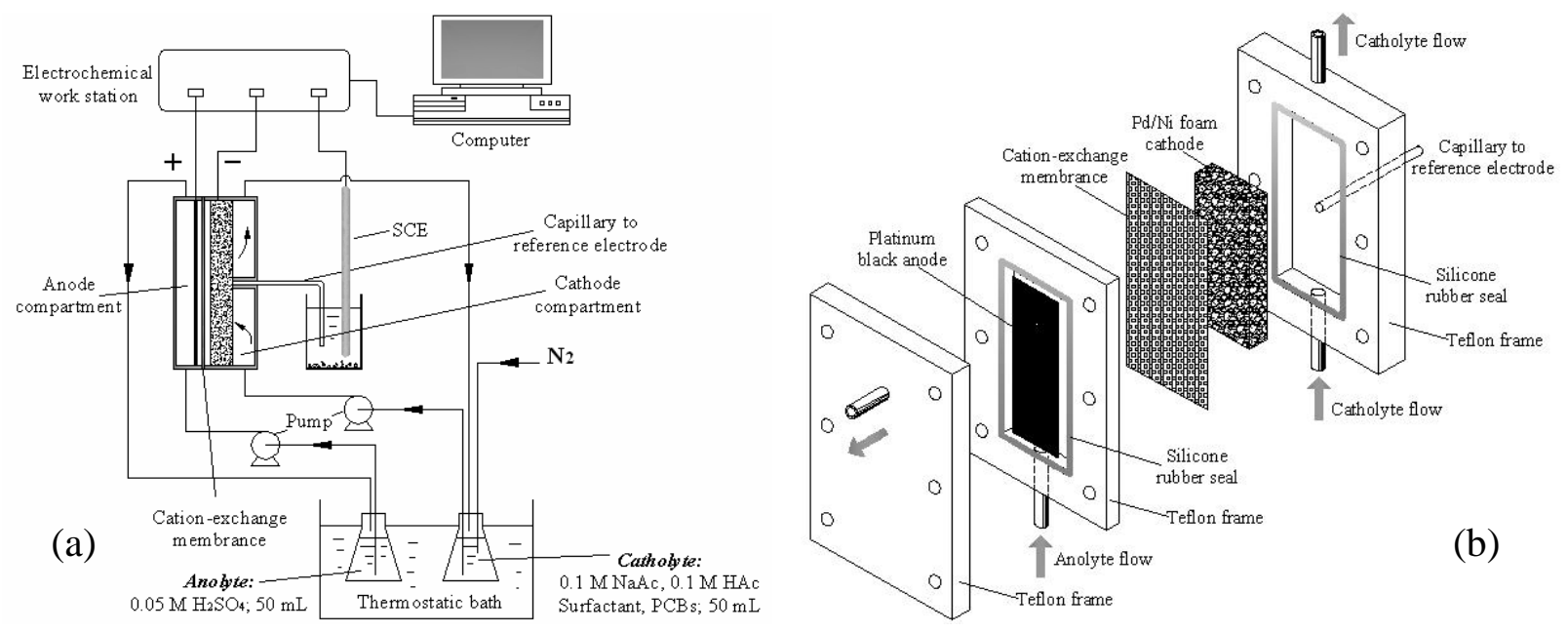

FIGURE S1. (a) Schematic view of the electrolytic system used for PCB ECH; (b) electrochemical reactor. 


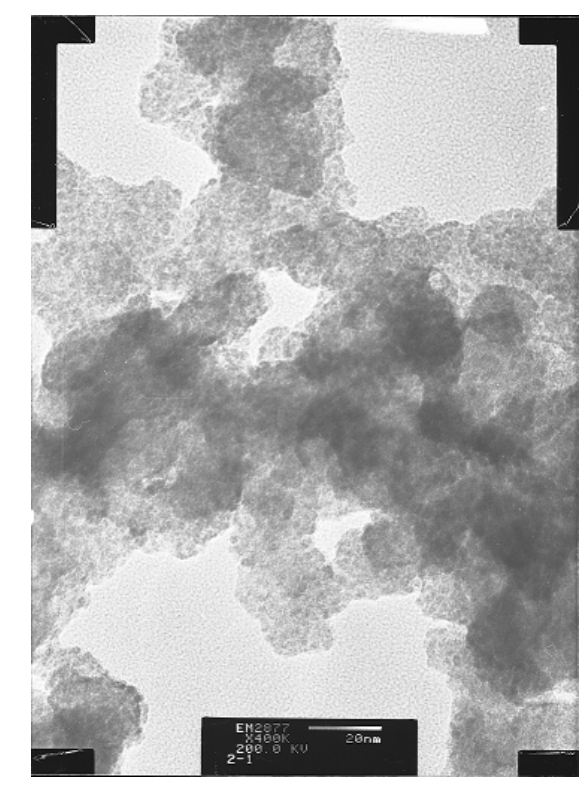

FIGURE S2. Transmission electron microscopy image of nanoscale Pd particles peeled from Pd/Ni foam.

Catalyst Characterization. Pd particles peeled from $\mathrm{Pd} / \mathrm{Ni}$ foam electrode in water by ultrasonic vibration was tested using the transmission electron microscopy (TEM) test. The results show that more than $90 \%$ of $\mathrm{Pd}$ particles were in the size range of $1-20 \mathrm{~nm}$. X-ray diffraction (XRD) analysis further proved the periodic lattice arrangement of $\mathrm{Pd}$ atoms, indicating the crystalline structure of the nanoscale particles, which has an average size of 6.9 $\mathrm{nm}$ using the standard Scherrer line-broadening approach. In addition, the surface area analyzer (Micromeritics ASAP 2010 Model) measurement suggest that BET specific surface area of the $\mathrm{Pd} / \mathrm{Ni}$ foam was $7.2784 \pm 0.0843 \mathrm{~m}^{2} / \mathrm{g}$, which greatly increased from the raw Ni foam $(1.4132 \pm$ $0.0796 \mathrm{~m}^{2} / \mathrm{g}$ ). These results suggested that the Pd was dispersed finely rather than forming clusters or films over the Ni foam surface. 


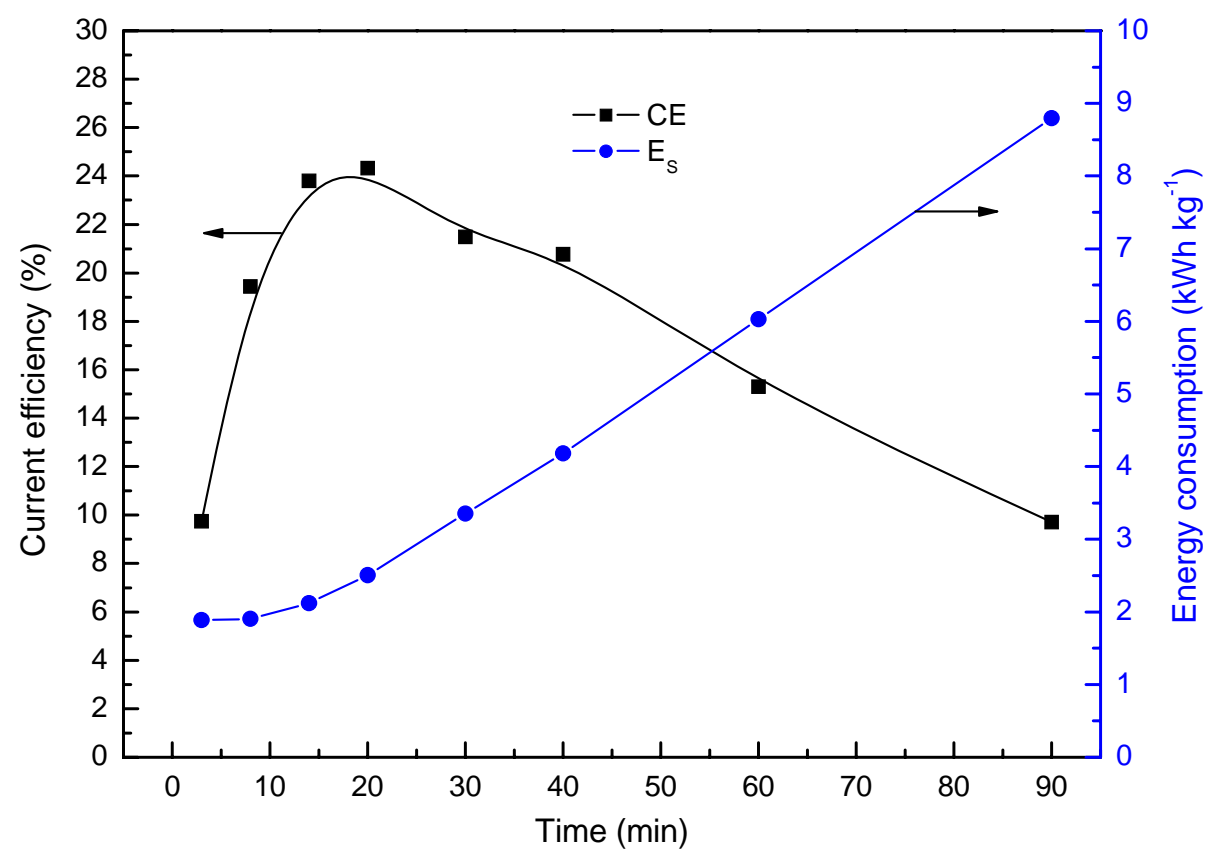

FIGURE S3. Current efficiency and energy consumption vs. electrolysis time for ECH of

\section{2,4,5-PCB. The conditions are as in FIGURE 1.}

Current Efficiency and Energy Consumption. Two key parameters for electrolysis system design, namely current efficiency (CE) and energy consumption $\left(E_{S}\right)$ were used to evaluate the ECH process of 2,4,5-PCB. The CEs used to producing biphenyl during 2,4,5-PCB electrolysis were in a range of $9.7-24.3 \%$ and the maximum value of CEs was found at about $20 \mathrm{~min}$. The decrease of CEs after 20min electrolysis could be owing to the rapid decrease of 2,4,5-PCB. The $E_{S}$ for the conversion of 2,4,5-PCB were in range of 1.9-8.8 $\mathrm{kWh} / \mathrm{kg}$. The CE and relatively low $E_{S}$ could facilitate the industrial application of the ECH of PCBs because Pd/Ni foam electrode showed high-performance ECH for 2,4,5-PCB in bulk electrolysis experiments. 